\title{
Immunoglobulin Administration and Ribavirin Therapy: Efficacy in Respiratory Syncytial Virus Infection of the Cotton Rat
}

\author{
WILLIAM C. GRUBER, SAMUEL Z. WILSON, BETHANY J. THROOP, AND PHILIP R. WYDE
}

Influenza Research Center, Baylor College of Medicine, Houston, Texas 77030

\begin{abstract}
We studied the effects of combined administration of human immunoglobulin (IVIG) and ribavirin aerosol on respiratory syncytial virus (RSV) infection in cotton rats (Sigmodon hispidus). Cotton rats assigned to receive combined therapy were administered Gamimune, a preparation of purified IVIG with a high titer of anti-RSV neutralizing activity, intraperitoneally $24 \mathrm{~h}$ prior to intranasal RSV challenge and then treated with ribavirin aerosol 3 days after challenge. Lung viral titers from these cotton rats (geometric mean titers [GMT] $\log _{10}=0.15 \pm 0.5$ ) were lower than titers from untreated animals (GMT, $\log _{10}$ $=3.7 \pm 0.6$ ) and animals treated with either IVIG alone (GMT, $\log _{10}=1.8 \pm 0.9$ ) or ribavirin alone (GMT, $\log _{10}$ $=1.9 \pm 1.1$ ). Only one of 12 cotton rats treated with both IVIG and ribavirin had a demonstrable titer of virus after RSV challenge. When IVIG administration was delayed until day 3 after virus challenge, lung viral titers were still lowest in animals receiving both IVIG and ribavirin. In comparison, there was no additive antiviral effect between IVIG and ribavirin against RSV infections of HEp-2 cells in vitro. Pathologic changes on histologic examination of pulmonary tissues from animals challenged with RSV were least prominent in animals treated with both IVIG and ribavirin. Despite the apparent absence of in vitro additive antiviral effect, combined use of IVIG and ribavirin was more efficacious against RSV infection in the cotton rat than use of either agent alone. (Pediatr Res 21: 270-274, 1987)
\end{abstract}

\section{Abbreviations}

RSV, respiratory syncytial virus IVIG, human immunoglobulin

TCID $_{50}$, tissue culture infections doses

MEM, minimal essential medium

SFU, syncytia forming units

PBS, phosphate-buffered saline

GMT, geometric mean titers

RSV is the most important viral cause of lower respiratory tract disease in infants and young children (1) and is associated with significant morbidity in children with underlying cardiopulmonary disease (2). Until an effective vaccine against RSV can be developed, effective protection of high-risk infants against

Received April 14, 1986; accepted October 23, 1986.

Address for correspondence William C. Gruber, M.D., Pediatric Infectious Diseases, Vanderbilt University Medical Center, Nashville, TN 37232.

Address for reprint requests Philip R. Wyde, Ph.D., Influenza Research Center, One Baylor Plaza, Houston, TX 77030.

Supported by the National Institutes of Health contract NOI-AI62522. serious RSV disease may require treatment with combinations of currently available therapeutic agents.

Previous studies have shown that parenteral inoculation of IVIG containing a high titer of anti-RSV neutralizing activity can provide significant protection in the cotton rat against RSV infection, (3) and significantly reduce the amount of virus shed from the airways of RSV infected owl monkeys (4). Ribavirin (1- $\beta$-D-ribofuranosyl-1,2,4-triazole-3-carboxamide), a synthetic nucleoside that possesses inhibitory activity against RSV in vitro, has been shown to reduce the amount of RSV in lung tissue of experimentally infected cotton rats (6) and appears to exert a beneficial effect on the course of human RSV infection (7-9). The present study evaluated the combined effect of IVIG and ribavirin on the quantity of RSV contained in lungs of experimentally infected cotton rats and the effect of this combination on histopathologic evidence of infection.

\section{METHODS}

Animals. Cotton rats (Sigmodon hispidus) used in these studies were derived from two pairs of animals obtained from the Small Animal Section, Veterinary Resources Branch, Division of Research Services, National Institutes of Health. Test animals were 2-3 wk old at the start of each experiment. All animals were maintained in cages with barrier filters and fed food and water ad libitum.

Experimental design. Animals were randomly assigned to receive IVIG alone (group 1), ribavirin alone (group 2), IVIG + ribavirin (group 3), or no treatment (group 4). Animals designated to receive prophylaxis with IVIG (groups 1 and 3) were lightly anesthetized with ether and $0.5 \mathrm{ml}$ of IVIG was administered intraperitoneally. Twenty-four $\mathrm{h}$ after administration of antisera, the cotton rats from all four groups were anesthetized with ether, bled from the retroorbital venous plexus, and challenged intranasally with $10^{4}$ median $\mathrm{TCID}_{50}$ of RSV. Three days after virus challenge animals in groups 2 and 3 were treated with ribavirin delivered continuously by small particle aerosol for 18 h. On day 4 after challenge, blood specimens were obtained, and lungs were harvested from each animal. Cotton rats that were treated with ribavirin were sacrificed $3 \mathrm{~h}$ after aerosol delivery was completed. The left lingular region of each lung was placed in formalin, embedded in paraffin, sectioned $(5 \mu)$, and stained and hematoxylin and eosin. These sections were rank ordered blindly based on overall assessment of histopathology. The remaining lung tissue was homogenized and assessed for virus titer. Otherwise identical experiments were performed in which IVIG administration was delayed until day 3 after RSV intranasal challenge. In order to rule out in vitro neutralization of RSV by IVIG or ribavirin that might be present in lung tissue at the time that the lungs were harvested, parallel experiments were performed in which cotton rats were assigned to groups $1-4$ as noted above, but the animals were not challenged with RSV. Instead, 
lungs from these animals were harvested, homogenized, and serially diluted 2-fold in 96-well microtiter plates, and $35 \mathrm{TCID}_{50}$ of RSV were then added to each well. After plates were maintained $2 \mathrm{~h}$ at room temperature, $0.05 \mathrm{ml}$ of a suspension of HEp2 cells $\left(10^{4}\right.$ cells $\left./ \mathrm{ml}\right)$ were added to each well. At the end of a 7day incubation period at $37^{\circ} \mathrm{C}$ in a humidified incubator with $5 \% \mathrm{CO}_{2}$, the extent of inhibition of the challenge virus by lung homogenates from each group was determined.

Virus. The Long strain of RSV, propagated in HEp-2 cells, was used in all experiments.

Virus assay. Lungs were homogenized in $1 \mathrm{ml}$ of Earle's MEM (Gibco, Grand Island, NY) supplemented with $5 \%$ fetal calf serum (Gibco) and assayed immediately for the presence of RSV. Briefly, half $\log _{10}$ dilutions of lung specimens were added in duplicate to monolayers of HEp-2 cells (Flow Laboratories, McLean, VA) grown in 16-mm diameter wells. After a 60-min adsorption period at $37^{\circ} \mathrm{C}$ in a $5 \% \mathrm{CO}_{2}$ atmosphere, Earle's MEM containing $5 \%$ fetal calf serum was added, and the plates were placed in a $37^{\circ} \mathrm{C}\left(5 \% \mathrm{CO}_{2}\right)$ incubator for 5 days. At that time the monolayers were fixed and stained with $0.5 \%$ aqueous crystal violet in $70 \%$ methanol and SFU counted. Viral titers were expressed as $\log _{10}$ SFU/lung.

Immune sera. Gamimune (Lot no. 45N18; Cutter Biologicals, Berkeley, CA), a preparation of purified human IgG with a RSV neutralizing antibody titer of $1: 3162$, was used in all experiments.

Ribavirin administration. Ribavirin (Viratek, ICN Pharmaceuticals, Costa Mesa, CA) was prepared as a $15 \mathrm{mg} / \mathrm{ml}$ solution and delivered by small particle aerosol generated by a Collison nebulizer over $18 \mathrm{~h}$, as previously described $(10,11)$.

Antibody assay. Anti-RSV antibody in cotton rat sera was measured by modification of a microneutralization assay previously described (12). Briefly, all sera were heated at $56^{\circ} \mathrm{C}$ for 30 min prior to testing. Duplicate 0.025 -ml volumes of 2 -fold serum dilutions of the heat-inactivated sera were then prepared in 96well plates and mixed with equal volumes of a RSV pool containing approximately $100 \mathrm{TCID}_{50}$ per $0.025 \mathrm{ml}$. After $2 \mathrm{~h}$ at room temperature $0.05 \mathrm{ml}$ of a suspension of HEp-2 cells $\left(10^{4}\right.$ cells $/ \mathrm{ml}$ ) was added to each well and the plates were incubated at $37^{\circ} \mathrm{C}$ in a humidified incubator with $5 \% \mathrm{CO}_{2}$. The test was read each day for 5 days. Titers were defined as the reciprocal of the last dilution of antisera that reduced $\mathrm{SFU} \geq 50 \%$ as compared to the mean number of SFU in virus control wells.

Antiviral effect of IVIG and ribavirin in vitro. The effects of IVIG and ribavirin alone and in combination on RSV infection in tissue culture were studied. Gamimune was diluted with PBS (pH 7.2) to a starting concentration providing an RSV neutralizing titer of 1:8. Ribavirin was similarly diluted to a starting concentration of $40 \mu \mathrm{g} / \mathrm{ml}$. Two-fold dilutions using MEM supplemented with $5 \%$ fetal calf serum were made with each agent alone and with respect to each other in 96-well microtiter plates. One hundred TCID 50 of RSV were added to each well. After incubation at room temperature for $2 \mathrm{~h}, \mathrm{HEp}-2$ cells were added to each well and plates were incubated at $37^{\circ} \mathrm{C}\left(5 \% \mathrm{CO}_{2}\right)$ for 5 days at which time each well was observed for cytopathic effect. Titer was defined as the reciprocal of the last dilution of antiserum $\left(\log _{2}\right)$, ribavirin, or a combination of the two which reduced SFU $\geq 50 \%$ in comparison to virus plus medium controls.

Statistics. GMT, SD, $\chi^{2}$, and F tests were performed as described by Sokal and Rohlf (13). Bonferroni $\chi^{2}$ tests, $t$ tests, or Wilcoxon rank sum tests were performed on paired groups (14).

\section{RESULTS}

Cotton rat sera from animals which received IVIG $24 \mathrm{~h}$ prior to virus challenge (groups 1 and 3) demonstrated an RSV neutralizing antibody GMT $\left(\log _{2}\right)$ of 4.9 and $5.0 \pm 1.4$, respectively, on the day of challenge (day 0) and a GMT of 3.8 and $3.5 \pm 1.0$, respectively, on the day of sacrifice (day 4). Sera from untreated cotton rats or animals that received ribavirin alone did not demonstrate detectable RSV neutralizing activity (Table 1).
Virus titers and the percentage of cotton rats in each group which had virus isolated from lung tissue are shown in Table 2. Initial analysis using the $\chi^{2}$ test indicated that there were significant differences between groups $\left(\chi^{2}=27.6, p<0.001\right)$. However, among groups treated with either IVIG or ribavirin alone, the number of animals with detectable virus in lung tissue did not differ significantly from the untreated group. In contrast, the group of cotton rats treated with both IVIG and ribavirin had significantly fewer animals that had detectable lung virus titers when compared to groups of untreated animals or to cotton rats treated with either agent alone $(p<0.001, p<0.005$ using Bonferroni $\chi^{2}$ ).

Differences in lung virus titers were observed between groups of animals $(\mathrm{F}=36.57, p<0.001)$ (Table 2). Animals receiving ribavirin or IVIG alone had significantly lower titers of RSV in lung tissue than untreated animals $(p<0.003$, Bonferroni twotailed $t$ test) but were not significantly different from each other. Animals that received both agents, however, had significantly lower virus titers than untreated animals $(p<0.001)$ or animals receiving either IVIG or ribavirin alone $(p<0.005)$. When IVIG administration was delayed until day 3 after RSV challenge, the group of cotton rats treated with both IVIG and ribavirin still had fewer animals with detectable lung virus. In addition, lung virus titers were lowest in animals that received both agents. However, these results were not statistically significant when compared to results obtained from animals which received either ribavirin or IVIG alone (Table 3 ).

Normal cotton rat lung histology is shown in Figure 1. Histopathologic examination of lung tissue from untreated animals and from those receiving ribavirin alone revealed peribronchial

Table 1. Neutralization titers to RSV in microneutralization assays of sera from cotton rats administered IVIG, ribavirin, $I V I G+$ ribavirin, or no treatment

\begin{tabular}{|c|c|c|c|}
\hline \multirow[b]{2}{*}{ Group } & \multirow{2}{*}{ Treatment $(n)$} & \multicolumn{2}{|c|}{$\begin{array}{l}\text { Neutralization titer } \\
\left(\log _{2}\right)(\mathrm{GMT} \pm \mathrm{SD})^{*}\end{array}$} \\
\hline & & Day 0 & Day 4 \\
\hline 1 & IVIG (15) & $4.9 \pm 1.0$ & $3.8 \pm 1.0$ \\
\hline 2 & Ribavirin (15) & $<2$ & $<2$ \\
\hline 3 & Ribavirin + IVIG (14) & $5.0 \pm 1.4$ & $3.5 \pm 1.0$ \\
\hline 4 & None (16) & $<2$ & $<2$ \\
\hline
\end{tabular}

* Titer $=$ reciprocal of the last dilution $\left(\log _{2}\right)$ which produced a $50 \%$ or greater reduction in syncytia in comparison to virus + media controls.

Table 2. Isolation and titers of RSV from lung homogenates of cotton rats administered IVIG, ribavirin, or IVIG + ribavirin

\begin{tabular}{clcc}
\hline Group & Treatment $(n)$ & $\begin{array}{c}\text { No. of } \\
\text { cotton rats } \\
\text { with detectable } \\
\text { virus }(\%)^{*}\end{array}$ & $\begin{array}{c}\text { Titer of virus } \\
\text { in lung } \\
\text { homogenates } \\
\left(\log _{10} \text { SFU/ }\right. \\
\text { lung) } \\
(\mathrm{GMT} \pm \mathrm{SD}) \dagger\end{array}$ \\
\hline 1 & IVIG $(11)$ & $9(80)$ & $1.8 \pm 0.9 \ddagger$ \\
2 & Ribavirin $(12)$ & $10(83)$ & $1.9 \pm 1.1 \ddagger$ \\
3 & IVIG + ribavirin $(12)$ & $1(8) \S$ & $0.14 \pm 0.5 \|$ \\
4 & None & $12(100)$ & $3.7 \pm 0.6$ \\
\hline
\end{tabular}

$* \chi^{2}=27.6, p<0.001$.

$\dagger \mathrm{F}=35.57, p<0.001$. Lung virus titers less than $1 \log _{10}$ were considered to be $0 \log _{10}$ for purposes of statistical analysis.

$\ddagger p<0.003$ in comparison to no treatment group (Bonferroni twotailed $t$ test).

$\S p<0.001$ in comparison to no treatment group, $p<0.005$ in comparison to groups treated with ribavirin alone or IVIG alone (Bonferroni $\chi^{2}$ ).

$\| p<0.001$ in comparison to GMT of no treatment group, $p<0.005$ in comparison to GMT of group treated with ribavirin alone or IVIG alone (Bonferroni two-tailed $t$ test). 
and peribronchiolar inflammatory infiltrates with ballooning, clumping, and exfoliation of eosinophilic epithelial cells. Little difference in the histopathology of the lungs in these two groups was observed (Figs. 2 and 3). IVIG administration appeared to protect against tissue damage, as evidenced by preservation of lung architecture and reduction in pulmonary inflammatory infiltrates which were most prominent in animals receiving both IVIG and ribavirin (Fig. 4). Lungs from cotton rats that received IVIG prior to RSV challenge followed by ribavirin therapy on day 3 demonstrated histology which was difficult to distinguish from that of uninfected lungs.

Parallel experiments performed in animals that were not challenged with RSV revealed that in vitro neutralization of added virus ( $35 \mathrm{TCID}_{50}$ ) by homogenates of lungs from treatment groups was no different than that produced by homogenates of lungs from untreated animals (Table 4). These data suggest that reduction of viral titers observed in treatment groups was not due to in vitro inactivation of virus by residual IVIG or ribavirin in harvested lungs, but rather represented an in vivo effect.

We performed in vitro tests to look for synergistic or additive effects when ribavirin and IVIG were combined. Gamimune was

Table 3. Isolation and titers of RSV from lung homogenates of cotton rats treated on day 3 with IVIG, ribavirin, or IVIG + ribavirin

\begin{tabular}{clcc}
\hline Group & Treatment $(n)$ & $\begin{array}{c}\text { Titer of virus } \\
\text { in lung } \\
\text { cotton rats } \\
\text { with detectable } \\
\text { virus }(\%)^{*}\end{array}$ & $\begin{array}{c}\text { homogenates } \\
\left(\log _{10} \text { SFU/ }\right. \\
\text { lung) } \\
(\mathrm{GMT} \pm \mathrm{SD}) \dagger\end{array}$ \\
\hline 1 & IVIG (8) & $6(75)$ & $1.5 \pm 0.9 \ddagger$ \\
2 & Ribavirin $(7)$ & $6(86)$ & $2.1 \pm 1.1$ \\
3 & IVIG + Ribavirin $(8)$ & $3(38)$ & $0.75 \pm 1.0 \S$ \\
4 & None (8) & $8(100)$ & $3.4 \pm 0.7$
\end{tabular}

$* \chi^{2}=6.42, p<0.1$.

$\dagger \mathrm{F}=11.01, p<0.001$. Lung virus titers less than $1 \log _{10}$ were considered to be $0 \log _{10}$ for purposes of statistical analysis.

$\$ p<0.05$ in comparison to no treatment group (Bonferroni twotailed Wilcoxon rank sum test).

$\S p<0.05$ in comparison to no treatment group, $p>0.1$ to groups treated with IVIG or Ribavirin alone (Bonferroni two-tailed Wilcoxon rank sum test). diluted to a concentration providing an RSV neutralizing titer of 1:8. (A 1:16 dilution of the preparation did not inactivate virus.) Ribavirin alone inactivated RSV at a concentration of 20 $\mu \mathrm{g} / \mathrm{ml}$ but $10 \mu \mathrm{g} / \mathrm{ml}$ did not limit viral replication in HEp-2 cells. However, the combination of a 1:16 dilution of the above IVIG preparation and $10 \mu \mathrm{g} / \mathrm{ml}$ of ribavirin prevented viral cytopathic effect in HEp-2 cells. Further dilution of either agent in combination with a fixed concentration of the other failed to inactivate the virus. Therefore in vitro additive effect of the two agents in combination was minimal.

\section{DISCUSSION}

In 1973, Parrott et al. (15) observed that infants less than 2 months of age who had high titers of maternally derived antiRSV serum antibodies experienced bronchiolitis less frequently than older infants who had lower levels of serum antibodies. Subsequently, Glezen et al. (12) and others (17) demonstrated that RSV disease occurs less often and is less severe in infants with high levels of passively acquired maternal RSV antibodies. Experiments in the cotton rat indicated that a high titer of passively administered serum RSV neutralizing antibody protected the lungs against infection with RSV and that the levels of serum antibody correlated with resistance to infection (16). In subsequent experiments passive inoculation with IVIG provided significant protection against RSV lung infection in the cotton rat (3) and significantly reduced amounts of virus shed from the noses and airways of RSV-infected owl monkeys (4).

Although purified IVIG preparations with high titers of antiRSV neutralizing activity might be useful in protecting high-risk infants, some investigators have reported considerable overlap in the level of maternally derived serum neutralizing antibodies among infants who develop severe RSV disease and those who do not (17). This finding suggests that administration of IVIG containing RSV neutralizing antibody may not provide uniform protection for high-risk infants and combination therapy with another agent active against RSV might prove to be more effective.

Ribavirin (1- $\beta$-D-ribofuranosyl-1,2,4-triazole-3-carboxamide), a synthetic nucleoside that is a structural analog of guanosine, has shown promising activity against RSV in vitro and in vivo. This drug when delivered by aerosol reduces the amount of RSV in lung tissues of experimentally infected cotton rats (6) and appears to ameliorate human infection with particularly striking improvement in arterial oxygen pressures in infected infants (9).

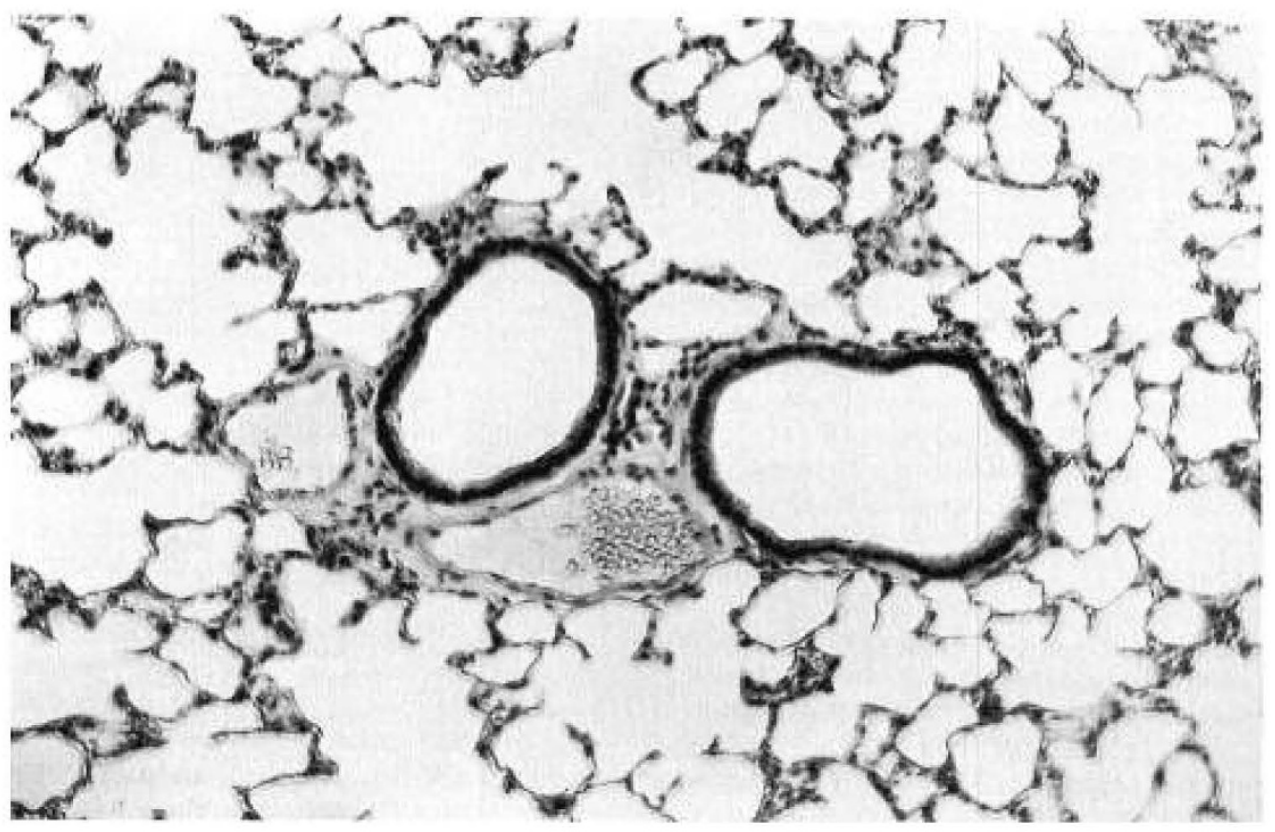

Fig. 1. Normal cotton rat lung. This and all subsequent sections were prepared by fixing lung tissue in formalin and staining paraffin-embedded sections with hematoxylin and eosin. Magnification, $\times 100$. 


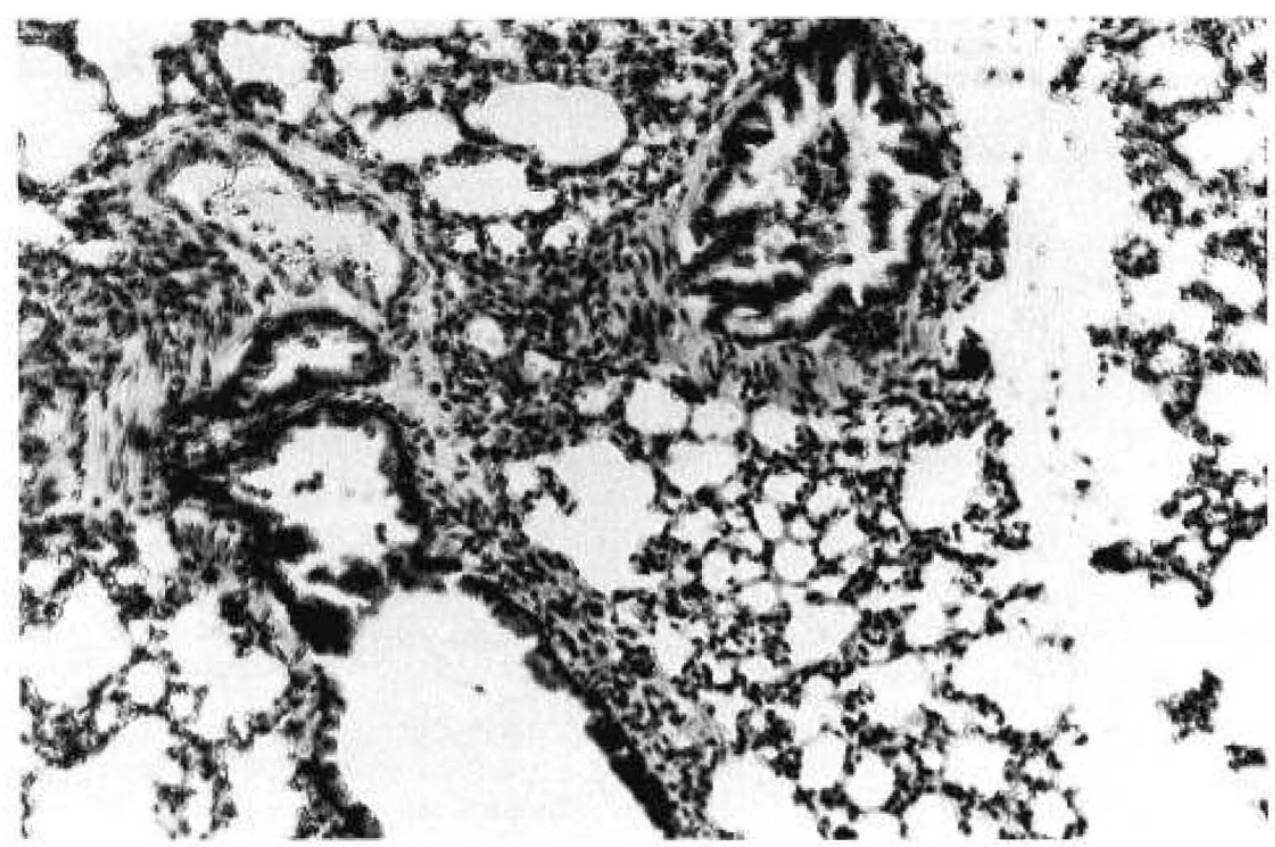

Fig. 2. Control cotton rat lung. The animal was challenged intranasally with RSV on day 0 and sacrificed on day 4. Peribronchiolar inflammation is present and bronchiolar epithelial cells show ballooning, clumping, and exfoliation. Magnification, $\times 100$.

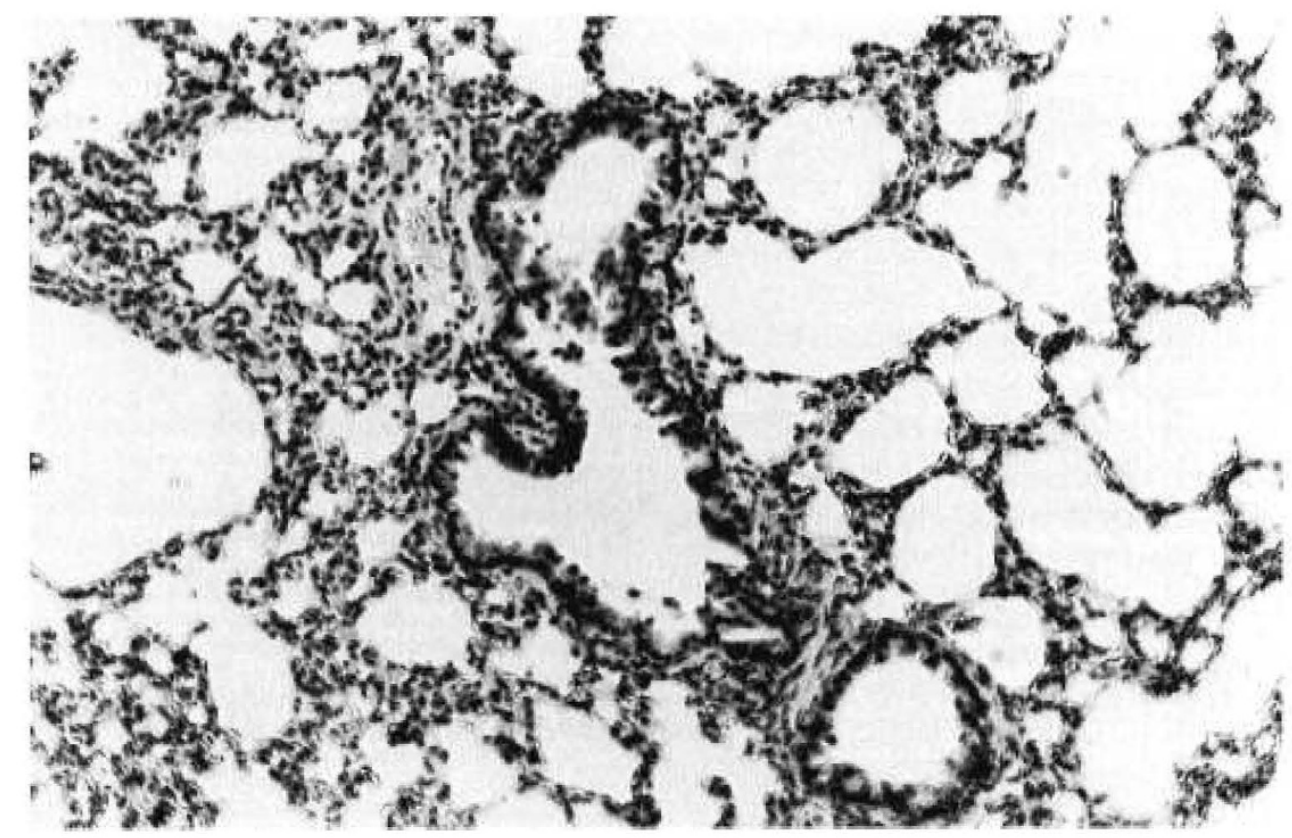

Fig. 3. Lung from ribavirin-treated cotton rat. Animal was challenged intranasally with RSV day 0 , treated with ribavirin day 3 , and sacrificed day 4. Bronchiolar epithelial cell stratification, clumping and cell loss is similar to that seen in control lungs. Magnification, $\times 100$.

However, subjective improvement is often subtle (8), and in one study the proportion of patients shedding RSV from their nasal secretions during the first 3 days of ribavirin therapy did not differ from a group receiving placebo (9). Combination of ribavirin with another agent might provide improved protection against RSV infection.

In the current study we investigated whether administration of IVIG in combination with ribavirin therapy by small particle aerosol provided advantages over either agent alone against RSV infection in the cotton rat. GMT of anti-RSV specific neutralizing antibody in serum of cotton rats who received IVIG were comparable to passively acquired antibody titers of infants protected against severe RSV disease (12). Animals who received IVIG or ribavirin alone showed a significant reduction in amounts of virus isolated from lung homogenates, but numbers of animals with detectable virus did not differ from untreated animals. In comparison, animals treated with both IVIG and ribavirin had significantly lower lung viral titers than untreated animals or animals treated with either agent alone, and only one of $12(8 \%)$ cotton rats who received IVIG prophylaxis followed by ribavirin therapy on day 3 had detectable virus in lung tissue at the time of sacrifice. This latter regimen appeared to preserve normal lung histology. These results could not be explained by in vitro inactivation of virus, nor was an in vitro additive effect demonstrable between IVIG and ribavirin. We obtained similar results when IVIG administration was combined with ribavirin therapy on day 3, although results were less striking; three of eight $(38 \%)$ cotton rats who received combination therapy had 


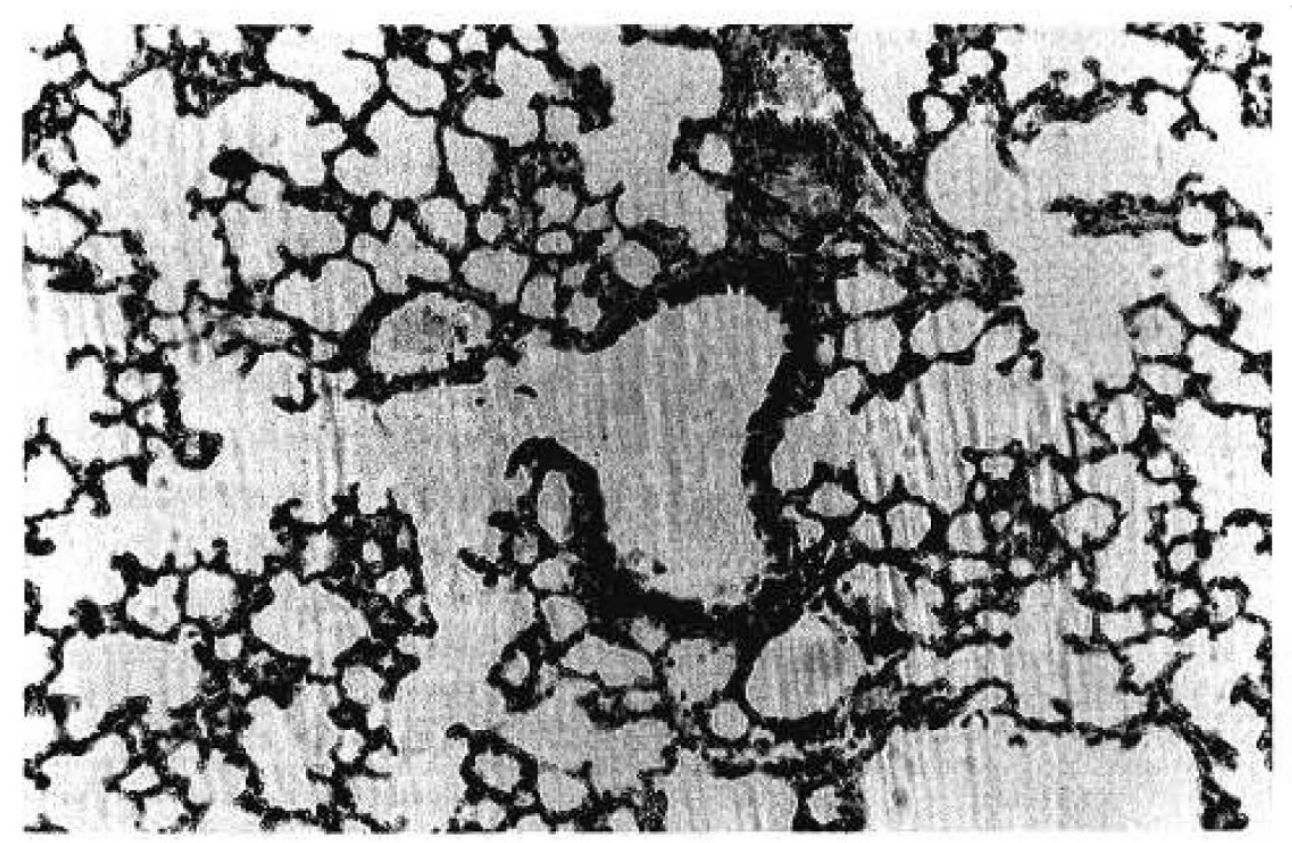

Fig. 4. Lung from IVIG and ribavirin-treated cotton rat. The animal was challenged intranasally with RSV on day 0, treated with IVIG and ribavirin on day 3 , and sacrificed on day 4 . Bronchiolar architecture is relatively preserved with mild epithelial stratification and cell loss. Magnification, $\times 100$.

Table 4. Neutralization of RSV $\left(35 T C I D^{50}\right)$ in vitro by lung homogenates from cotton rats administered IVIG, ribavirin, or $I V I G+$ ribavirin

\begin{tabular}{clc}
\hline Group & \multicolumn{1}{c}{ Treatment $(n)$} & $\begin{array}{c}\text { Neutralization titer }\left(\log ^{2}\right) \\
(\mathrm{GMT} \pm \mathrm{SD})^{*,} \dagger\end{array}$ \\
\hline 1 & IVIG (4) & $1.25 \pm 0.5$ \\
2 & Ribavirin (4) & $1.25 \pm 0.5$ \\
3 & Ribavirin + IVIG (4) & $1.5 \pm 0.6$ \\
4 & None (4) & $1.5 \pm 0.6$ \\
\hline
\end{tabular}

* Titer = reciprocal of the last dilution $\left(\log _{2}\right)$ which produced a $50 \%$ or greater reduction in syncytia in comparison to virus + media controls. $\dagger \mathrm{F}=1.3, p>0.25$.

detectable lung virus at the time of sacrifice and mild pulmonary histopathology was noted.

A possible interpretation of the above findings is that human anti-RSV IgG antibody combined with cellular or humoral immune responses of the cotton rat to limit RSV replication and that ribavirin therapy following infection neutralized the remaining low titer of virus. This interpretation is supported by the fact that animals that received IVIG prior to RSV infection demonstrated less histopathology than animals that did not, and animals that received both ribavirin and IVIG had the greatest preservation of normal lung appearance. Further studies are indicated to determine how IVIG and ribavirin interact with local antibody and cellular elements (e.g. macrophages, cytotoxic $\mathrm{T}$ cells) to limit RSV infection.

The success of IVIG combined with ribavirin in eradicating RSV and protecting the lungs of cotton rats may have important implications for successful intervention against RSV infection in high-risk infants. A potential strategy would be to administer IVIG prophylaxis to high-risk infants at a time when RSV is identified in the community in the hope of preventing RSV infection. Infants who develop RSV illness despite prophylaxis could then be treated with ribavirin. Alternatively, IVIG and ribavirin could be administered in combination during established RSV infections of high-risk infants. Experience with combination therapy in the cotton rat suggests that such strategies may prove more effective than those that rely on either IVIG or ribavirin alone. Clinical trials are indicated to determine the best approach.

\section{REFERENCES}

1. Henderson FW, Collier AM, Clyde WA Jr, Denny FW 1979 Respiratorysyncytial-virus infections, reinfections and immunity: a prospective longitudinal study in young children. N Engl J Med 300:530-534

2. MacDonald NE, Hall CB, Suffin SC, Alexson C, Harris PJ, Manning JA 1982 Respiratory syncytial viral infection in infants with congenital heart disease. N Engl J Med 307:397-400

3. Prince GA, Hemming VG, Horswood RL, Chanock RM 1985 Immunoprophylaxis and immunotherapy of respiratory syncytial virus infection in the cotton rat. Virus Res 3:193-206

4. Hemming VG, Prince GA, Horswood RL, London WT, Murphy BR, Walsh EE, Fischer GW, Weisman LE, Baron PA, Chanock RM 1985 Studies of passive immunotherapy for infections of respiratory syncytial virus in the respiratory tract of a primate model. J Infect Dis 152:1083-1087

5. Hruska JH, Sidwell RW, Khare GP, Witkowski JT, Allen LB, Robins RK 1973 In vitro effect of 1-D-ribofuranosyl-1,2,4-triazole-carboxamide (Virazole, ICN 1229) on deoxyribonucleic acid and ribonucleic acid viruses. Antimicrob Agents Chemother 3:235-241

6. Hruska JF, Morrow PE, Suffin SC, Douglas RG Jr 1982 In vitro inhibition of respiratory syncytial virus by ribavirin. Antimicrob Agents Chemother 21:125-130

7. Hall CB, McBride JT, Walsh EE, Bell DM, Gala CL, Hildreth S, Ten Eyck LG, Hall WJ 1983 Aerosolized ribavirin treatment of infants with respiratory syncytial viral infection. N Engl J Med 308:1443-1447

8. Taber LH, Knight V, Gilbert BE, McClung HW, Wilson SZ, Norton J, Thurson JM, Goodon WH, Afusso RL, Schlaudt WR 1983 Ribavirin aerosol treatment of bronchiolitis associated with respiratory syncytial virus infection in infants. Pediatrics 72:613-618

9. Hall CB, McBride JT, Gala CL, Hildreth SW, Schnabel KC 1985 Ribavirin treatment of respiratory syncytial viral infection in infants with underlying cardiopulmonary disease. JAMA 254:3047-3051

10. Young HW, Dominik JW, Walker JS, Larson EN 1977 Continuous aerosol therapy system using a modified collison nebulizer. J Clin Microbiol 5:131136

11. Wilson SZ, Knight V, Wyde PR, Drake S, Couch RB 1980 Amantadine and ribavirin aerosol treatment of influenza $A$ and $B$ infection in mice. Antimicrob Agents Chemother 17:622-648

12. Glezen WP, Paredes A, Allison JE, Taber LH, Frank AL 1981 Risk of respiratory syncytial virus infection for infants from low-income families in relationship to age, sex, ethnic group and maternal antibody level. J Pediatr 98:708-715

13. Sokal RR, Rohlf FJ 1969 Biometry. WH Freeman Co., San Francisco.

14. Glantz SA 1981 Primer of Biostatistics. McGraw-Hill Book Co., New York, pp 87-124

15. Parrott RH, Kim HW, Arrobio JO. Hodes DS, Murphy BR, Brandt CD Camargo E, Chanock RM 1973 Epidemiology of respiratory syncytial virus infection in Washington, D.C. II Infection and disease with respect to age, immunologic status, race and sex. Am J Epidemiol 98:289-300

16. Prince GA, Horswood RL, Chanock RM 1985 Quantitative aspects of passive immunity to respiratory syncytial virus infection in infant cotton rats. J Virol 55:517-520

17. Ogilvie MM, Vathenen AS, Radford M, Codd J, Key S 1981 Maternal antibody and respiratory syncytial virus infection in infancy. $J$ Med Virol 7:263-271 